\title{
Política de seguridad en México: combate al narcotráfico. Entre la seguridad nacional y la seguridad pública*
}

\section{Francisco Sánchez Espinoza** Claudia Juárez Jaimes***}

\begin{abstract}
RESUMEN
En el presente trabajo, se expone un recorrido histórico de la politica de combate a las drogas en México, a la par de su relación con los Estados Unidos. Más adelante, se analiza cómo el desarrollo de esta política en la actualidad se encuentra entre garantizar la seguridad nacional y la seguridad pública. Por ello, es necesario tener una aproximación teórica del término seguridad y sus diversas acepciones y, al mismo tiempo, revisar las reglas en materia de seguridad. De tal forma, será posible entender cómo la seguridad nacional se ha vinculado con la seguridad pública para hacer frente al narcotráfico con el uso de las Fuerzas Armadas.
\end{abstract}

\section{PALABRAS CLAVE}

Estado, politica, narcotráfico, seguridad pública, seguridad nacional.

\begin{abstract}
In the present work it is proposed a historical route of the policy of the fight against drugs in Mexico is exposed, without neglecting the relationship with the United States, to further analyze how the development of this policy at present is between two issues, ensure national security and public safety, so it is necessary to have a theoretical-conceptual approach to the term Security and its various meanings and, at the same time, a revision of the rules on security, so that we can understand how National Security has been linked to Public Security to confront Drug Trafficking with the use of the Armed Forces.
\end{abstract}

\section{KEYWORDS}

State, Politics, Drug Trafficking, Public Security, National Security

\footnotetext{
*Artículo recibido el 28 de marzo de 2018 y aceptado para su publicación el 7 de junio de 2018

**Profesor investigador en la Benemérita Universidad Autónoma de Puebla, México. (frasaes_7@ @hotmail.com) orcid. org/0000-0003-0229-1000

***Eresada del posgrado en Ciencias Políticas de la Benemérita Universidad Autónoma de Puebla, México (claudia.juarez18@gmail.com) orcid.org/0000-0001-5668-6628
} 


\section{SUMARIO}

1. Antecedentes

2. Construyendo la seguridad entre lo nacional y lo público

3. Política de seguridad en México: Felipe Calderón y Enrique Peña Nieto

4. Conclusión

\section{Antecedentes}

En un inicio, el narcotráfico se localizó al norte del país. El clima favorable para la producción del opio y el contexto de la Segunda Guerra Mundial permitieron la siembra, el cultivo y la producción de drogas. De tal manera, se desarrolló un mercado que empezaría a tener nuevas maneras de operar y que daría pauta a la conformación de algunos de los cárteles más importantes, como el cártel de Juárez, el de Sinaloa y el del Golfo.

Los Estados Unidos, por su parte, intentaban establecer relaciones más claras y fáciles respecto al tráfico de drogas -desde principios del siglo con las políticas y leyes de prohibición de la droga-. Sin embargo, no se daba cumplimiento a las promesas, acuerdos y reuniones entre las naciones para darle respuesta al problema, en parte por la diferencia de prioridades y de recursos que tenían los países en los años cuarenta y cincuenta.

La preocupación de Estados Unidos por acontecimientos en su interior como revueltas y movimientos sociales que se relacionaron con el consumo de marihuana después de la posguerra- y el clima político-electoral de la época propiciaron que el gobierno de Richard Nixon (1969-1974) tomara medidas drásticas al plantear la guerra contra las drogas. Por tal motivo, en la década de 1970, los gobiernos de México y de Estados Unidos decidieron colaborar más en el combate al tráfico de marihuana y heroína que el primer país producía e importaba al segundo.

El resultado fue una reducción en la producción de amapola y marihuana y una parcial disminución en las exportaciones, en el marco de la Operación Cóndor, la cual tenía como finalidad erradicar plantíos de droga en la zona del triángulo dorado (Sinaloa, Chihuahua, Durango). Sin embargo, durante este periodo, se desatendió la corrupción de las corporaciones policiales mexicanas, el mercado de las drogas en el país y la demanda americana de ellas. Además, dicha operación propició la expansión del narcotráfico en México. Así, se repartieron nuevas plazas y se crearon nuevos cárteles en diferentes partes del territorio, por ejemplo, el Cártel de Guadalajara, liderado por Ernesto Fonseca Carrillo y Rafael Caro Quintero y, más tarde, por Miguel Ángel Félix Gallardo. 
Fue en ese momento que la estrategia de combate a las drogas se empezó a militarizar. Las fuerzas militares asumieron el cargo tanto de la erradicación de los cultivos ilícitos como de enfrentar a las organizaciones de narcotraficantes que se dedicaban a las demás actividades relacionadas con la droga. El Cártel de Guadalajara recibió un golpe duro con la detención de sus líderes, debida al asesinato de Enrique Camarena, agente de la DEA (Drug Enforcement Administration) que realizaba operaciones de investigación encubierto. Ese acontecimiento tensó la relación entre México y los Estados Unidos. Por su parte, los cárteles tuvieron un reacomodo, no sólo por la captura de los capos, sino también por la muerte de Amado Carrillo, líder del Cártel de Juárez, dos hechos fundamentales que definieron una serie de violentos reacomodos de los grupos dedicados al narcotráfico. ${ }^{1}$

A finales del siglo xx, la estructura del narcotráfico se vio fortalecida por el control centralizado de los cárteles y la corrupción política, hasta ser una empresa de comercio criminal con nuevas actividades delictivas, como la piratería, trata de personas, secuestro, robo con violencia y extorsión. Entonces, a principios del siglo xxI, creció su poder político, económico y social, en un contexto de transición democrática, donde la rotación rápida de élites permitió que las organizaciones criminales se reconfiguraran y acumularan poder, ganancias y territorio.

De acuerdo con Eduardo Guerrero, ${ }^{2}$ las condiciones estructurales del país que permitieron ese escenario fueron la creciente demanda por parte del país vecino -mayor consumidor de droga en el mundo-; la existencia de varias comunidades en condiciones de pobreza -que pueden ser la plataforma social del crimen organizado debido a la relación de clientelismo que se establece entre los narcotraficantes y los líderes de la comunidad-; la inversión económica por parte de los narcotraficantes en la construcción de obras sociales y la debilidad institucional del gobierno. Esto último, como consecuencia de su bajo desempeño en los indicadores de eficacia gubernamental, Estado de derecho, rendición de cuentas, control de corrupción e inestabilidad de los conflictos.

Por su parte, Mónica Serrano ${ }^{3}$ señala que la evolución del mercado crimi231 nal se debe a cuatro factores: la feroz expansión del mercado asociada con el surgimiento de una economía de cocaína, el endurecimiento de la diplomacia

\footnotetext{
1 Ravelo, Ricardo, Los capos. Las narco-rutas de México, México, Plaza y Janés, 2006.

${ }^{2}$ Guerrero Gutiérrez, Eduardo, "Narcotráfico S. A.", Revista Nexos. [Consulta: 17 de diciembre, 2017]. Disponible en: http://www.nexos.com.mx/?p=15083

${ }^{3}$ SerRano, Mónica, "Narcotráfico y gobernabilidad en México", Dialnet. [Consulta: 28 de noviembre, 2017]. Disponible en: http://dialnet.unirioja.es/servlet/articulo?codigo=2873255
} 
antinarcóticos en los Estados Unidos, la debilidad de la economía y la apertura política en México.

Ambos investigadores mencionan factores internos y externos. Lo cierto es que, en condiciones de debilidad, la economía informal crece. Esto da pauta a negocios ilícitos y manejo de dinero en grandes cantidades, instrumento de las organizaciones criminales para corromper y sobornar a políticos, policías, funcionarios o jueces. Con ello, se crea un aparato de seguridad en torno al negocio; así, la discrecionalidad de las burocracias las transforma en empresas corruptas que propician la impunidad.

Jorge Chabat ${ }^{4}$ expone que en 2006 el presidente Felipe Calderón heredó un complicado escenario en materia de seguridad, caracterizado por el control del crimen organizado en algunos territorios de la república mexicana. Este contexto incluía una guerra entre cárteles de la droga causante de los altos niveles de violencia; la renuencia del gobierno de Fox para usar la fuerza pública; conflictos con los Estados Unidos por la narcoviolencia en la frontera; flujo estable de drogas hacia los Estados Unidos - que continuó a pesar de las políticas antinarcotráfico del anterior presidente-, y un aumento considerable del consumo de drogas ilícitas en México.

En este periodo, se detectaron nueve organizaciones: el Chapo Guzmán en Sonora; el cártel de Juárez en Chihuahua, Coahuila, Yucatán, y en disputa por Tamaulipas; el cártel de Tijuana en Baja California y en Morelos; el cártel de Sinaloa en Sinaloa; el cártel del Golfo en disputa por Tamaulipas, Michoacán, Guanajuato, Veracruz y Yucatán; el cártel de los hermanos Amezcua en Colima; el cártel de la familia Díaz Parada en Oaxaca; el cártel de los hermanos Valencia Cornelio en Michoacán. ${ }^{5}$

En esta situación y en un marco político marcado por una crisis de legitimidad, Felipe Calderón y su equipo presidencial anunciaron en diciembre de 2006 su estrategia contra el narcotráfico y el crimen organizado, e implementaron algunos operativos policiaco-militares en todo el territorio nacional. Esto fue la llamada guerra contra el narcotráfico, ${ }^{6}$ la primordial estrategia de dominación política del régimen mexicano.

\footnotetext{
${ }^{4}$ Chabat, JoRge, "La respuesta del gobierno de Felipe Calderón al desafío del narcotráfico: entre lo malo y lo peor", en Arturo Alvarado y Mónica Serrano (coords.), Los grandes problemas de México, México, Colmex, 2010.

${ }^{5}$ Cunjama, Emiılo, Jóvenes en riesgo, pandillas y delincuencia organizada en México, México, Tirant lo Blanch, 2014, p. 147.

${ }_{6}^{6}$ Presidencia de la República, Anuncio de la operación Conjunta Michoacán, inicio de la nueva estrategia de seguridad de combate al narcotráfico, México, Presidencia de la República, 2006.
} 
El narcotráfico y los delitos que lo acompañan se volvieron el enemigo común por combatir, en aras de la seguridad nacional y había que hacerles frente en pro de la seguridad pública. Las fuerzas armadas encabezaron la pelea, por lo cual se abrió el debate en torno a la seguridad que el gobierno garantiza en su política frontal contra el enemigo. En ésta, se vinculan los conceptos de seguridad nacional y de seguridad pública en relación con las atribuciones y responsabilidades que tienen las Fuerzas Armadas.

Hay que hacer hincapié en que, lejos de traer mayor seguridad al país, esta medida ha exacerbado la violencia y la inseguridad. El uso del ejército en labores civiles y la desarticulación de las bandas delictivas, lejos de traer beneficios, agravaron los niveles de violencia y la violación a los derechos humanos. Los cárteles de la droga, al fragmentarse y transformarse en mafias locales, vinieron a incrementar la incidencia de delitos como la extorción, el secuestro y el robo vehicular. ${ }^{7}$

A pesar de que hubo expectativas positivas en los primeros años del gobierno de Enrique Peña Nieto respecto al combate a la delincuencia y la inseguridad, con un discurso basado en la planeación y prevención, la situación se mantuvo similar a la del gobierno anterior. Incluso, se puede decir que en años recientes empeoró, debido al mal manejo de la estrategia de seguridad. ${ }^{8}$ Entre 2013 y 2015, se reportaron 50998 casos de homicidio, más de 11400 que los registrados en el mismo periodo de Felipe Calderón (39 526), es decir, se dio un aumento de casi 30\% en la incidencia del delito. ${ }^{9}$

Las manifestaciones persistentes de la violencia, el aumento de los delitos de alto impacto propagados en los estados que tenían una baja incidencia delictiva y la permanencia del negocio del tráfico de drogas han dado cuenta de la ineficacia del gobierno para solucionar el problema. Por el contrario, se ha agravado con la política de seguridad, cuya premisa es el combate frontal contra el narcotráfico. Ello ha provocado la fragmentación del tejido social, la desarticulación en las relaciones sociales, la desconfianza intrapersonal e institucional, además

\footnotetext{
${ }^{7}$ MARINA, SAndRA, "En seguridad, sexenios de avances y retrocesos", El Financiero. [Consulta: 13 de septiembre, 2017]. Disponible en: http://www.elfinanciero.com.mx/politica/en-seguridad-sexenios-de-avances-y-retrocesos.ht/m

${ }^{8}$ Hubo pocos cambios en la política de Peña Nieto para realmente detener la violencia en el país debido a que la Administración ha mantenido la estrategia y cometido los mismos errores de Calderón: se enfocó principalmente en dar seguridad inmediata en áreas donde la pelea entre los grupos del narcotráfico ha surgido de nuevo, como en Jalisco, Tamaulipas y el Estado de México. Es decir, hubo una expansión de la narcoviolencia. Véase CARRASCo, Jorge, "La violencia crece y Peña Nieto se pasma", Revista Proceso, agosto, 2016. [Consulta: 17 de octubre, 2017]. Disponible en: http://www.proceso.com.mx/450082/la-violencia-crece-pena-nieto-se-pasma

${ }_{9}^{9}$ Ángel, Arturo, "En cada día del 2015 asesinaron 51 personas en México", Vanguardia. [Consulta: 12 de abril, 2016]. Disponible en: http://www.vanguardia.com.mx/artículo/en-cada-dia-del-2015-asesinaron-51-personas-en-mexico
} 
de las experiencias traumatizantes para las personas que han presenciado o han sido víctimas de un delito. ${ }^{10}$

\section{Construyendo la seguridad entre lo nacional y lo público}

El concepto de seguridad se encuentra fijado en la trayectoria del liberalismo clásico, en el binomio libertad y orden. No podría existir una libertad real sin un orden establecido en la sociedad, garantizado por un Estado legítimo. La libertad se debe fundar en una conciencia social y una idea de justicia social, cuyo sustento sea el orden dinámico. Esto con el fin de ayudar a la mayoría a tener una mejor vida, mediante la seguridad. Por tanto, salvaguardar la vida, la propiedad, las pertenencias, los intereses y el derecho a la libertad está relacionado con la seguridad y el deseo de mantenerla dentro del estado liberal. Esto representa un aspecto clave en la corriente contractualista. ${ }^{11}$

En su acepción simple, y con base en el Diccionario esencial de la lengua española en su versión 2006, la seguridad deriva del adjetivo securus y, a su vez, del verbo curare. Se entiende como "cualidad de seguro", protección, "libre y exento de todo peligro, daño o riesgo", y concierne a los estados y a los individuos. También se relaciona con la preservación del orden y defensa de la libertad, la ausencia de amenazas a los valores adquiridos y, al mismo tiempo, la ausencia de miedo a que esos valores sean atacados. ${ }^{12}$ La seguridad ha sido un aspecto importante en la construcción del Estado moderno, desde las monarquías, donde ya se daban estrategias para mantener seguros a los reyes y príncipes en un Estado absolutista, hasta la demanda de seguridad de las personas, los bienes y servicios, y el comercio, durante el desarrollo y transición a la sociedad contractual-mercantil.

Uno de los pensadores clásicos que pone énfasis en este punto es Thomas Hobbes, ${ }^{13}$ quien expone que el Estado se funda en la contradicción entre las pasiones humanas y las leyes de la naturaleza. Esto es la contradicción en-

\footnotetext{
${ }^{10}$ Las políticas prohibicionistas y de combate, en su afán de control, se han olvidado de los derechos fundamentales y fortalecen el problema que dicen querer solucionar. Véase VegA, Armando, "El narcotráfico de drogas: más allá de la represión", Revista LiberAddictus, núm. 105. [Consulta: 18 de febrero, 2016]. Disponible en: http://www.liberaddictus.org/v_imprimir.php?articulo=934

${ }^{11}$ López Portillo, ERnesto, "Seguridad pública y democracia: hacia la seguridad ciudadana -relativizar al poder frente a la libertad-", en Arturo Alvarado y Sigrid Arzt (coords.), El desafío democrático de México: seguridad y estado de derecho, México, Colmex, 2001.

${ }^{12}$ Santos, Mario, El modelo general de administración estratégica de la seguridad nacional multidimensional, México, Centro de Estudios Navales, 2014, p. 113.

${ }^{13}$ La idea de que la seguridad individual tiene que ser conferida al Estado, poder absoluto, puede verse en HoBBES, Thomas, Leviatán, México, Fondo de Cultura Económica, 1992.
} 
tre las normas establecidas por la razón, con el fin de preservar la vida, y la inclinación de la humanidad por un afán de poder que encuentra su límite en el temor a la muerte. Esta última es el límite de la potencia expansiva del hombre, lo cual lo mueve a conformar un Estado por el deseo de la autoconservación: el bien supremo, seguir viviendo.

Cuando el hombre tiene la sensación de ser amenazado, toma conciencia y decide establecer un orden, constituyendo el mayor poder de los humanos: el Leviatán, el monstruo bíblico que salvaguarda y protege lo justo, esto es no atentar contra la vida. Los que estén de acuerdo se someterán a las reglas de este gran animal con poder supremo y absoluto sobre todos. Así, se presenta el reconocimiento del poder soberano y de las leyes; la voluntad colectiva cargada de razón lo hará posible. Es ahí donde el Estado encuentra su razón de ser: garantizar la vida y las relaciones de la comunidad política que lo conforman.

En su libro El contrato social Rousseau ${ }^{14}$ define que dicho contrato es parte de la constitución de un pacto social. Éste se manifiesta como la asociación que protege y defiende con la fuerza común a las personas que la constituyen. Se forma así un orden público y un cuerpo político que conforma el Estado activo, donde el sujeto (soberano) de poder tiene que cumplir con los compromisos civiles legítimos, dar vialidad a las acciones y pedimentos comunes del pueblo, debido a la gracia, fuerza y poder que el pueblo le ha confiado. Éste, a su vez, como participante en la autoridad, está sometido a las leyes del Estado.

En este sentido, la búsqueda de protección y resguardo ante cualquier amenaza, tanto interna como externa, hace que se constituyan elementos organizativos de articulación y coerción del poder en torno a la seguridad. Ello, a su vez, remite a un elemento instrumental de legitimidad. Dicha legitimidad la tiene el Estado, como estructura organizacional en su papel de garante de la seguridad. Esto debido a que tiene el monopolio de los poderes coercitivos y del uso de la fuerza que le permite ser, por una parte, una instancia de dominación y, por otra parte, es instancia de coordinación de las decisiones colectivas, mediante sistemas administrativos, jurídicos, tributarios, burocráticos y coercitivos. Tales sistemas le permiten al Estado lograr su jurisdicción sobre un territorio, bajo la legalidad del derecho racional.

El Estado debe estar constituido por un poder político que, en palabras de John Locke, ${ }^{15}$ tenga el derecho de hacer y dictar leyes que regulen y preserven la vida, la libertad y la propiedad, así como también el derecho a emplear su

\footnotetext{
${ }^{14}$ Rousseau, Jean-Jacques, El contrato social, México, Grupo Editorial, 2005.

${ }^{15}$ Locke, John, Segundo tratado sobre el gobierno civil, México, Alianza, 2004, p. 9.
} 
propia fuerza. Para tales fines sirven los poderes Ejecutivo y Legislativo de la sociedad civil, que está conformada por aquellos que están unidos y tienen establecida una ley común y una judicatura a la cual apelar para decidir sus controversias y castigar a los infractores de la ley.

En resumen, el Estado moderno se configura como un sistema de elementos diferenciados e interconectados. Es un organismo legal y legítimo al cual la sociedad, como ente organizado, le confirió el poder para ejercer sus derechos y obligaciones, y cuya función gira en torno también de validar el derecho y los órganos que la conforman. La actividad del Estado, realizada por el Gobierno (poder del Estado), se compendia en actos jurídicos, materiales, organizaciones y tareas que se llevan a cabo por mandato de ley. Esto con el propósito de cumplir los intereses nacionales, entre ellos, se encuentra propiciar la seguridad. ${ }^{16}$

Michel Foucault ${ }^{17}$ es uno de los grandes pensadores que tratan la relación entre el Estado y la seguridad. Señala que este concepto surge junto con el liberalismo y que tiene el objetivo de garantizar que los individuos o la colectividad estén expuestos lo menos posible a peligros. Por tanto, el Estado lleva a cabo procedimientos de control, coacción y coerción en torno a la salud, el crimen, así como el combate a las conductas antisociales y la defensa frente a amenazas externas al Estado, identificadas, principalmente, en la acción de otros Estados.

Anteriormente, la seguridad se percibía bajo el postulado de que la primordial amenaza provenía del exterior, de Estados que venían a atentar contra la seguridad del país. Por tal motivo, se realizaban estrategias tradicionalistas, fundamentadas en una concepción militar, territorial y estatocéntrica. ${ }^{18}$ Así, el Estado es la unidad básica del sistema internacional y la clave de la política de seguridad, mientras el conflicto militar es un elemento primordial para entender en sí misma la seguridad. ${ }^{19}$

\footnotetext{
${ }^{16}$ Véase SAntos, MarIO, El modelo general de administración estratégica de la seguridad nacional multidimensional, México, Centro de Estudios Superiores Navales, 2014, p. 38.

${ }^{17}$ Foucault, Michel, El nacimiento de la biopolítica, México, Fondo de Cultura Económica, 2010.

${ }^{18}$ La seguridad se relaciona con el paradigma estatocéntrico, que es una concepción convencional anterior a la Guerra Fría y se centraba en los temas político-militares asociados con la doctrina de la seguridad nacional, la cual privilegiaba el uso de la fuerza, en defensa del Estado. Véase González, Patricia, "Seguridad estatocéntrica y derechos humanos: Ios peligros para la democracia", XXVI Congreso de la Asociación Latinoamericana de Sociología, Guadalajara, México, 2007.

${ }^{19}$ Para entender esta postura sobre la seguridad, es necesario remitirse a los conflictos bélicos que afectaron a los paises en esos años (desde 1939 a 1962), pasando por la Segunda Guerra Mundial y el periodo de la Guerra Fría. Durante éstos, lo importante era proporcionar la defensa nacional para mantener la seguridad interna frente a amenazas externas contra el Estado, el cual era el único que podia hacerles frente, debido a su poder.
} 
Cuando el ser humano se volvió el referente de la seguridad, al ser concebido integralmente, se fundó el paradigma antropocéntrico. Este paradigma conjunta diversas expresiones de seguridad, de acuerdo con las implicaciones que conlleve cada uno. De tal modo, seguridad común se refiere a la mejora de la calidad de vida interna del país; la seguridad colectiva recurre a la violencia para salvaguardar los intereses nacionales; seguridad humana o seguridad cooperativa es aquella que, mediante la cooperación entre países en un proceso de construcción de confianza, diversos actores participan por el bien común; entre otros. ${ }^{20}$

Uno de los conceptos más estudiados es el de seguridad nacional, pues se ha transformado a lo largo del tiempo. Surgió en los Estados Unidos, en 1947, con el documento National Segurity Act (26 de junio de 1947). ${ }^{21}$ Más tarde, se amplió en relación con los acontecimientos de la Guerra Fría conduciéndolo a temas sobre uso de fuerza, diplomacia y capacidades militares. ${ }^{22}$

Con los atentados del 11 de septiembre del 2001, se replanteó el concepto de seguridad nacional y se incorporaron amenazas a la seguridad, tanto externas como internas. Por ello, la seguridad nacional pasó a ser un fenómeno multidimensional que enfrenta diversas amenazas. ${ }^{23}$

\footnotetext{
${ }^{20}$ LABORIE, MARIO, La evolución del concepto de seguridad, Madrid, Instituto español de estudios estratégicos, 2011.

${ }^{21}$ La Ley de la Seguridad Nacional de 1947 promueve un programa integral para la seguridad futura de Estados Unidos, a través del establecimiento de nuevas políticas y procedimientos para los departamentos, organismos y funciones del Gobierno, en relación con la seguridad nacional. Cabe señalar que el concepto de seguridad nacional surge con la conformación del Estado moderno, con el establecimiento de normas e instituciones que regulan las estructuras sociales bajo los principios de soberania y territorialidad.

${ }_{22}$ Ortega, Carlos, "Hacia una política de seguridad y defensa de México", Revista del Centro de Estudios Superiores Navales, 2013, pp. 22-27.

${ }^{23}$ Cfr. BARRón, Diana, La asimétrica distribución del ingreso como amenaza a la seguridad nacional, Tesis de licenciatura, Escuela de Ciencias Sociales, UDLAP, Puebla, 2003.
} 


\begin{tabular}{|c|c|c|}
\hline & & Cuadro 1 \\
\hline & Las amenazas a la se & guridad nacional, según tipo de interferencia e impactos \\
\hline \multirow{5}{*}{ Interferencias } & Antagonismos & $\begin{array}{l}\text { Oposición deliberada a la consecución o preservación de los objetivos } \\
\text { nacionales. }\end{array}$ \\
\hline & Amenaza & $\begin{array}{l}\text { Acción o situación que puede hacer peligrar la seguridad y defensa } \\
\text { nacionales. }\end{array}$ \\
\hline & Factor adverso & $\begin{array}{l}\text { Dificultades u obstáculos que se interponen pasivamente a la consecución o } \\
\text { mantenimiento de objetivos fijos. }\end{array}$ \\
\hline & Presiones & $\begin{array}{l}\text { Fuerza o coacción respaldada por la capacidad, que pretenden afectar } \\
\text { intereses del Estado. }\end{array}$ \\
\hline & $\begin{array}{l}\text { Presiones } \\
\text { dominantes }\end{array}$ & $\begin{array}{l}\text { Presión o antagonismo con suficiente capacidad para enfrentar al poder } \\
\text { nacional, y que amenaza los objetivos nacionales permanentes y/o política } \\
\text { nacional, y pueden resultar de los intereses de algún otro Estado o grupo } \\
\text { nacional. }\end{array}$ \\
\hline \multirow{4}{*}{ Según su impacto } & Externo & Tipo militar. Defensa del territorio de un pais de ataques bélicos. \\
\hline & Internas o domésticas & Tipo económico-social, desigualdad, distribución del ingreso-político. \\
\hline & Interdomésticas & $\begin{array}{l}\text { Afectan al Estado en el aspecto nacional y tienen efectos en el ámbito } \\
\text { exterior, como la migración. }\end{array}$ \\
\hline & Transnacionales & $\begin{array}{l}\text { Amenazas donde no se conocen fronteras y tienen repercusiones en una } \\
\text { región geográfica, como el narcotráfico; o el fundamentalismoideológico o } \\
\text { religioso. }\end{array}$ \\
\hline \multicolumn{3}{|c|}{ lente: Elaboración a partir de Barrón, 2003.} \\
\hline
\end{tabular}

Las amenazas, como se puede apreciar en el cuadro 1, pueden ser interferencias u obstáculos para la preservación de los intereses del Estado, o peligros que, de acuerdo con su impacto, afectan el ámbito externo e interno, a los cuales el Estado debe hacer frente en los dos ámbitos debido a su característica interdoméstica o transnacional.

La seguridad exterior remite a la protección del país en el espacio territorial, aéreo y marítimo frente a otros Estados, para preservar la libertad, la paz y la soberanía nacional. La seguridad exterior consiste, entonces, en el mantenimiento del Estado y la protección de los intereses nacionales en lo internacional y trasnacional. Mientras, la seguridad interior se relaciona con preservar el orden establecido. Ésta se enfoca en sostener, asegurar y conservar la seguridad del Estado, mediante acciones políticas, sociales y económicas que garanticen un clima propicio en el país, al combatir las presiones y los antagonismos que se presenten, a la vez que se cumplen los objetivos nacionales. ${ }^{24}$

\footnotetext{
24 "Entendemos a la seguridad interior como la situación de seguridad civil, económica, política y social existente en el interior de los límites legal-institucional del Estado; al mismo tiempo que entendemos a la seguridad exterior como la situación de seguridad del Estado en relación con la inserción política externa del mismo o a la preservación de su
} 
La seguridad nacional no solamente se enfoca en conservar y defender el territorio, sino también a la población y las instituciones, de lo que ponga en peligro o afecte al Estado. De esta manera, se vincula el concepto de seguridad nacional con el de seguridad pública, para hacerle frente a los peligros.

Anterior al concepto de seguridad pública, se empleaba el de orden público, con la finalidad de mantener el orden a través de los cuerpos policiales. La función de éstos era velar por la adecuación de las conductas a las normas, en un marco de seguridad concebido de manera amplia y vinculado con la seguridad del Estado.

Ahora, la seguridad pública se relaciona con la función gubernamental, con el control de la sociedad dentro del Estado. Engloba la defensa de las instituciones y el mantenimiento de la tranquilidad de la población; la defensa del derecho individual; la protección de las personas y sus bienes, así como el deber de perseguir y detener a los responsables de delitos. De tal modo, la seguridad pública implica "el conjunto de políticas y acciones coherentes y articuladas que tienden a garantizar la paz pública, a través de la persecución de los delitos y de las faltas contra el orden público, mediante el sistema de control penal y el de policía administrativa”. ${ }^{25}$

Por lo anterior, la seguridad pública busca proteger la integridad y derechos de las personas, defender la libertad, la seguridad, la propiedad, el orden y la paz pública. Para lograrlo, la autoridad debe focalizar sus acciones en la prevención, persecución, sanción de las infracciones y delitos cometidos, y en la reinserción social de los delincuentes. La seguridad pública, asimismo, busca resolver conflictos entre los integrantes de una misma sociedad, por medio de la impartición de justicia.

En este sentido, la seguridad pública tiene un valor político para el Estado, porque la actividad policiaca debe fortalecer el orden social, cuando sus acciones demuestran los valores de convivencia del Estado. Pero, cuando se realizan acciones contrarias, se puede provocar la irritación social y el aumento de un conflicto que propicie una amenaza a la paz de la sociedad.

Muchos autores señalan que el concepto de seguridad nacional envolvió al de seguridad pública, en referencia a las amenazas y peligros que combaten. ${ }^{26}$

integridad institucional o territorial frente a otros Estados." Véase SAin, MARCElo, "Condiciones institucionales del control parlamentario de las actividades y organismos de inteligencia del Estado", Seminario sobre control democrático de los organismos de seguridad interior en la República Argentina, Centro de estudios legales y sociales, Argentina, 1997, p. 140.

${ }^{25}$ González, Samuel, La seguridad pública en México, México, unam, 1994, p. 173.

${ }^{26}$ Principalmente, la discusión gira en torno a los delitos relacionados con el crimen organizado y el narcotráfico, problemáticas que tratan ambos tipos de seguridad. 
Según Raúl Benítez, "la seguridad pública comenzó a considerarse un asunto de seguridad nacional [...] por el aumento inusitado de delitos de alto impacto." ${ }^{27}$ En este tenor, la seguridad pública fue considerada como "materia principalmente policial y la seguridad nacional, como la necesidad de garantizar la viabilidad del Estado". ${ }^{28}$

María de la Luz Lima Las engloba las posturas anteriores, al exponer que "la seguridad pública es ahora un asunto de la seguridad nacional. Ambos se encuentran íntimamente vinculados, son condiciones necesarias para el desarrollo nacional, así como medios para vivir en democracia dando como resultado el desarrollo armónico del proyecto de nación". ${ }^{29}$

Ante estas manifestaciones, Ernesto López ${ }^{30}$ señala que la seguridad pública, lejos de propiciar las dinámicas y los procesos a los que hemos aludido, se centra en mantener la razón del Estado, sean o no buenos sus fines y acciones en torno a la sociedad y, particularmente, el ciudadano. Por lo tanto, expone que el concepto de seguridad ciudadana tiene la finalidad de ubicar al ciudadano como eje, razón de ser y destinatario prioritario de toda política de seguridad. Las diferencias son las siguientes:

${ }^{27}$ Benittez, Raúl, "México: seguridad pública y seguridad nacional. Desafíos militares", en La seguridad nacional integral en México, México, Universidad del ejército y fuerza armada Cesnav, 2013, pp. 93-113.

${ }^{28}$ Montero, Juan Carlos, "La estrategia contra el crimen organizado en México: análisis del diseño de la política pública", Revista Perfiles Latinoamericanos, núm. 39, p. 9.

${ }^{29}$ Lima Malvido, Maria de la Luz, "De la política criminal a la seguridad nacional", en Sergio García y Olga González (coords.), La situación actual del sistema penal en México, XI Jornadas sobre justicia penal, México, unAm - Inacipe, 2011, p. 402.

30 López PortILlo, ERnESTo, "Seguridad pública y democracia: hacia la seguridad ciudadana -relativizar al poder frente a la libertad-", en Arturo Alvarado y Sigrid Arzt (coords.), El desafio democrático de México: seguridad y estado de derecho, México, Colmex, 2001, p. 77. 
Cuadro 2

\begin{tabular}{|c|c|}
\hline & Cuadro 2 \\
\hline \multicolumn{2}{|c|}{ Características de la seguridad pública y la seguridad ciudadana } \\
\hline Seguridad pública & Seguridad ciudadana \\
\hline Doctrina de la razón del Estado & Estado democrático de derecho. \\
\hline Seguridad: atribución del poder & Seguridad: condición de libertad expresada en un derecho ciudadano. \\
\hline $\begin{array}{l}\text { Objetivo rector: garantizar el orden público (concepción mecanicista y } \\
\text { estática de la relación entre el individuo y las normas) }\end{array}$ & \multirow[t]{2}{*}{$\begin{array}{l}\text { Objetivo: garantizar el ejercicio de las actividades ciudadanas, bajo un enfoque dinámico y } \\
\text { flexible }\end{array}$} \\
\hline Conservación del statu quo & \\
\hline La seguridad es un fin en símismo. & La seguridad es un medio para alcanzar los fines democráticos \\
\hline $\begin{array}{l}\text { La responsabilidad es preservar el Estado como mecanismo de } \\
\text { poder. }\end{array}$ & La responsabilidad la tiene el gobierno y los gobernados en un diseño y control horizontal \\
\hline El individuo es un espectador pasivo de las acciones del Estado & $\begin{array}{l}\text { El individuo es ciudadano porque establece una relación activa frente a su derecho a la } \\
\text { seguridad }\end{array}$ \\
\hline $\begin{array}{l}\text { El control y la confianza no son necesarios debido a que la institución } \\
\text { pública y el individuo viven en paralelo }\end{array}$ & $\begin{array}{l}\text { El control y la confianza son reguladores, promovidos mediante la participación ciudadana y } \\
\text { la verificación pública del desempeño institucional }\end{array}$ \\
\hline $\begin{array}{l}\text { La ausencia de control ciudadano deriva en la nula calidad del } \\
\text { desempeño institucional, el decisionismo y la intuición }\end{array}$ & $\begin{array}{l}\text { El perfil institucional tiene un carácter técnico profesional, derivado de la combinación de } \\
\text { controles de calidad en el desempeño interno y externo. }\end{array}$ \\
\hline
\end{tabular}

González $^{31}$ confronta los puntos anteriores y menciona que la ausencia de un marco legal consistente en materia de seguridad nacional propicia un vacío cultural y doctrinal. Por ello, muchas personas se desconciertan con las actividades operativas de las fuerzas armadas al interior del país, pues dan por hecho que estas autoridades se involucran en las tareas de la seguridad pública. No obstante, en la realidad, realizan operaciones en el interior, en el marco de una seguridad nacional.

De este modo, las amenazas y peligros que enfrenta actualmente el Estado han obligado a reconfigurar los significados conceptuales de ambas seguridades, planteando un marco de cooperación y colaboración intergubernamental que engloba lo nacional y lo público, cuya vinculación se ha dado mediante el concepto de seguridad interior.

Pese a que existen ambivalencias en cómo se manejan los términos, la realidad da cuenta de que la seguridad nacional, en su división interior, reviste a la seguridad pública, lo cual se refleja en planes, acciones y operaciones que realizan los elementos del Estado. En ese contexto, todo lo que atente contra él se vuelve el enemigo, un enemigo que daña a las personas y al "bien común”.

\footnotetext{
${ }^{31}$ GonzÁlez, JaIme, "La seguridad interior en México: concepto y campo de acción", Revista del centro de estudios superiores navales, núm. 34, pp. 14-25.
} 


\section{Política de seguridad en México: Felipe Calderón y Enrique Peña Nieto}

Los debates en torno a la política de seguridad nacional y el concepto de seguridad nacional son relativamente recientes en nuestro país. Tanto los académicos como grupos de la sociedad civil han intentado esclarecer lo que representa el concepto. También las autoridades gubernamentales han hecho esfuerzos por definir, ampliar y diferenciar las categorías conceptuales de seguridad nacional, política de seguridad nacional y la misma doctrina de seguridad nacional, la cual rige los principios y valores de las demás. ${ }^{32}$

Estos debates y las transformaciones en los conceptos se ven permeados por connotaciones políticas e ideológicas. Éstas propician un planteamiento general de los acontecimientos que influyeron en dichos señalamientos: $a$ ) el final de la guerra fría; $b$ ) la transición política hacia la democracia; c) la relativización del concepto de soberanía en un mundo globalizado, y d) la crisis por causa del terrorismo internacional. ${ }^{33}$

En México, el concepto de seguridad nacional se adoptó en los años setenta, en el Reglamento Interior de la Secretaría de Gobernación, publicado en el Diario Oficial de la Federación en 1973. Después, el concepto se incorporó al plan nacional de desarrollo en la administración del presidente Miguel de la Madrid, de 1982 a $1988 .{ }^{34}$ El Plan Global de Desarrollo 1980-1982 estableció que la seguridad nacional sería llevada a cabo por las fuerzas armadas, cuya función sería

Reafirmar y consolidar la viabilidad de México como país independiente. Dentro de una visión conceptual propia a las condiciones mexicanas, la defensa de la integridad, la independencia y la soberanía de la nación se traducen en el mantenimiento de la normatividad constitucional y el fortalecimiento de las instituciones políticas de México. ${ }^{35}$

\footnotetext{
32 Véase Martinez, Alejandro, "Tres momentos para entender la seguridad nacional en México", Revista de El Colegio de San Luis, año 4, núm. 7, pp. 236-255. [Consulta: 12 de mayo, 2015]. Disponible en: http://www.redalyc. org/4262/426239582011.pdf

${ }^{33}$ Curzio, Leonardo, La seguridad nacional en México, México, unam, 2014.

${ }^{34}$ Ortega, Carlos, "Hacia una política de seguridad y defensa de México", Revista del Centro de Estudios Superiores Navales, año 3, núm. 34, pp. 22-27.

35 Poder Ejecutivo Federal, Plan global de desarrollo 1976-1982. [Consulta: 13 de noviembre, 2016]. Disponible en: http://ordenjurídico.gob.mx
} 
Debido a la naturaleza contextual que se vivía (la Guerra Fría), el Plan se enmarcó en una lógica de seguridad exterior, con el fin de mantener y salvaguardar la seguridad interior por medio de las Fuerzas Armadas, en función de proteger la soberanía del país. A partir de ello, la seguridad nacional se percibe como una forma de asegurar las condiciones de desarrollo nacional en un marco constitucional de libertad, paz y justicia social. Así, se procura una política pacifista que reitere el derecho y la cooperación internacional como una forma de garantizarla. La idea es tener un país seguro que proporcione la estabilidad interna en consenso y unidad nacional, bajo principios de libertad y derecho.

Sin embargo, algunos aspectos del concepto de seguridad devinieron con el cambio del partido en el poder. Así, se plasmaron cambios en el plan de desarrollo nacional de Vicente Fox. A partir de ello, se presume una crítica a lo que era la seguridad nacional en años anteriores, señalando que era usada para justificar actos ilegítimos de autoridad para procurar la permanencia del régimen, la continuidad partidista y los grupos de poder que reprimían y neutralizaban la oposición. Por tanto, se olvidaban de los objetivos centrales que conlleva la seguridad nacional.

En el plan, se establecieron las metas principales de la seguridad nacional: "velar por la protección y preservación del interés colectivo, evitando en lo posible o minimizando cualquier riesgo o amenaza a la integridad física de la población y de las instituciones. Para ello, el nuevo gobierno se propone emprender acciones efectivas contra la delincuencia organizada y el tráfico ilícito de drogas". ${ }^{36}$ El concepto usado en este plan corresponde a una visión amplia de la seguridad nacional. Así, enfatiza en la seguridad interior frente a las amenazas que atenten contra la integridad física de la población y de las instituciones, como "las que representen la pobreza y la desigualdad, la vulnerabilidad de la población frente a los desastres naturales, la destrucción ambiental, el crimen, la delincuencia organizada y el tráfico ilícito de drogas". ${ }^{37}$

El Plan Nacional de Desarrollo 2007-2012, del presidente Felipe Calderón, señala las directrices de la política de seguridad nacional y de seguridad pública trazadas en el Programa Nacional de Seguridad Pública. El plan está dividido en cinco ejes rectores: Estado de derecho y seguridad; economía competitiva y generadora de empleos; igualdad de oportunidades; sustentabilidad ambiental; democracia efectiva y política exterior responsable.

\footnotetext{
${ }^{36}$ Poder Ejecutivo Federal, Plan nacional de desarrollo 2001-2006, p. 89. [Consulta: 3 de diciembre, 2015]. Disponible en: http://wwww.dof.gob.mx/nota_detalle.php?codigo=766334\&ffecha=30/05/2001

${ }_{37}$ Poder Ejecutivo Federal, Plan nacional de desarrollo 2001-2006, p. 90. [Consulta: 3 de diciembre, 2015]. Disponible en: http://wwww.dof.gob.mx/nota_detalle.php?codigo=766334\&fecha=30/05/2001.
} 
El eje 1 manifiesta la importancia que tiene el Estado de derecho y su fortalecimiento para permitir el desarrollo humano, la justicia efectiva, el crecimiento económico y la rendición de cuentas, los cuales propician la confianza y la legitimidad de las instituciones. Para alcanzar estos propósitos, uno de los objetivos es "recuperar la fortaleza del Estado y la seguridad en la convivencia social mediante el combate frontal y eficaz al narcotráfico y otras expresiones del crimen organizado". ${ }^{38}$

Esto último se basa en que el narcotráfico, al ser una de las manifestaciones de la delincuencia organizada, reta al Estado y se convierte en una fuerte amenaza para la seguridad nacional. De tal modo, se hace necesaria la fuerza del Estado para recuperar espacios que han sido ganados en años anteriores por los narcotraficantes y el crimen organizado. Para ello, el plan incluye estrategias de eliminación de plantíos de enervantes e intercepción de cargamentos de droga por tierra, mar y aire; modernización de las Fuerzas Armadas con equipos de inteligencia e implementación en las fuerzas policiales de sistemas de inteligencia; abatir el narcomenudeo con operativos permanentes y atacar el lavado de dinero.

$\mathrm{Al}$ retomar este pequeño rubro del plan nacional de desarrollo, se observa algo común entre la seguridad nacional y la seguridad pública: ambas se van a encargar de combatir el narcotráfico y los delitos ocasionados por el crimen organizado. Como bien lo señala Montero, "el PND afirma que el crimen organizado es un asunto de seguridad nacional, por lo que sus líneas de acción se enfocan principalmente hacia la política de seguridad pública". ${ }^{39}$

Asimismo, el Programa Nacional de Seguridad Pública, que deriva del plan nacional de desarrollo, establece en su objetivo 2 el combate frontal al fenómeno delictivo y la consolidación del Estado de derecho con la coordinación y corresponsabilidad de los tres niveles de gobierno, mediante la estrategia nacional de prevención del delito y combate a la delincuencia, en el marco del Sistema Nacional de Seguridad Pública. ${ }^{40}$

Por lo anterior, una de las estrategias gira en torno a enfrentar los delitos de alto impacto, como los secuestros, homicidios dolosos y robos con violencia, mediante labores de prevención, investigación, persecución y sanción de delitos, a través de acciones conjuntas emprendidas con la Secretaría de Defensa Nacional y la Secretaría de Marina, así como con la Procuraduría General de la República, entre otras instancias.

\footnotetext{
${ }^{38}$ Objetivo 8 del Plan.

${ }^{39}$ Montero, Juan Carlos, "La estrategia contra el crimen organizado en México: análisis del diseño de la política pública", Revista Perfiles Latinoamericanos, año 39, p. 25.

${ }^{40}$ Diario oficial de la federación, Programa nacional de seguridad pública, 2008-2012.
} 
Se puede observar que existe una cooperación por parte de las instituciones encargas de propiciar la seguridad nacional y pública en materia de combate al narcotráfico, el crimen organizado y los delitos que cometen. El enemigo del Estado es el crimen organizado y la manera de enfrentarlo es la fuerza pública.

Los cinco pilares en los que se basó la política de seguridad de Calderón fueron operaciones conjuntas, con el apoyo de los gobiernos locales; mejora de las capacidades tecnológicas y operativas de las agencias del sector de seguridad; reformas al marco jurídico e institucional; una política activa de prevención del delito, y el fortalecimiento de la cooperación internacional. ${ }^{41}$ Los puntos clave de la política de seguridad pretendían efectuar estrategias punitivas para reducir los niveles de violencia. Sin embargo, ocasionaron mayor violencia e inseguridad en el país.

Por su parte, el plan nacional de desarrollo de Enrique Peña Nieto establece cinco ejes rectores: México en paz; incluyente; con educación de calidad; próspero, y con responsabilidad global. ${ }^{42}$ El primer eje expone las estrategias y líneas de acción con objetivos definidos para promover y fortalecer la gobernabilidad democrática; garantizar la seguridad nacional; mejorar las condiciones de seguridad pública; garantizar un sistema de justicia penal eficaz, expedito, imparcial y transparente; garantizar el respeto y protección a los derechos humanos y la erradicación de la discriminación, así como salvaguardar a la población, sus bienes y su entorno ante un desastre natural o humano.

En el plan nacional de desarrollo, se señala que la seguridad nacional contiene objetivos e intereses estratégicos nacionales, como

la protección de la nación frente a las amenazas y riesgos; la preservación de la soberanía e independencia nacionales y la defensa del territorio; el mantenimiento del orden constitucional y el fortalecimiento de las instituciones democráticas de gobierno; la preservación de la unidad de las partes integrantes de la federación [...] la defensa legítima del Estado respecto de otros Estados o sujetos de derecho internacional; y el desarrollo económico, social y político.

De acuerdo con este plan, una política integral de seguridad nacional deberá atender todos aquellos factores que puedan vulnerar el elemento humano del

\footnotetext{
${ }^{41}$ Guerrero Gutiérrez, Eduardo, "La estrategia fallida", Revista Nexos, diciembre, 2012. [Consulta: 24 de octubre, 2016]. Disponible en: http://www.nexos.com.mx/?P=leerarticuloctArticle=2103067

${ }^{42}$ Diario Oficial de la Federación, Plan nacional de desarrollo, 2013-2018. México.
} 
Estado. Por ello, se amplía el concepto de seguridad nacional para abarcar la protección de los derechos humanos. Así, adquiere un carácter multidimensional y permite la tranquilidad y seguridad mediante el combate a toda manifestación de violencia y delincuencia de alto impacto.

Para garantizar ese México con paz, la presidencia de la república hace hincapié en el desarrollo de capacidades de inteligencia, implantación de sistemas de investigación e información de datos generados por las autoridades, con el fin de aprovechar los avances tecnológicos y mantener la estabilidad con un apego al derecho. Presenta un diagnóstico donde expone las consecuencias de lo que dejó la estrategia del gobierno anterior con el combate frontal al crimen organizado. Señala, así, el vacío de poder que se generó dentro de los grupos delictivos, por la aprehensión y extradición de los líderes, lo cual provocó luchas violentas a lo largo del territorio y una mayor violencia que se refleja en una ampliación de delitos.

A pesar de este pequeño diagnóstico acertado de la situación, se les da prioridad a las Fuerzas Armadas. Esto debido a su función de mantener la seguridad exterior, pero prioritariamente interior por la violencia que ha generado el crimen organizado.

En esta ocasión, se insiste en un marco jurídico que proporcione certeza sobre la actuación del Ejército. Este marco debe procurar el respeto de los derechos humanos y la modernización institucional para fortalecer la capacidad del Estado. De tal modo, será posible un mejor intercambio de información. Asimismo, será posible la cooperación con las autoridades de los tres niveles de gobierno para preservar la integridad, estabilidad y permanencia del Estado. Por tanto, se necesitará la coordinación y cooperación internacional y el fortalecimiento de la inteligencia.

Según el plan, se procura fortalecer el Sistema de Inteligencia Militar y el Sistema de Inteligencia Naval, mediante el uso de herramientas tecnológicas, para integrarlos con diversas dependencias de la Administración Pública Federal y promover, con las instancias de la Administración Pública Federal y las

246 Fuerzas Armadas, una doctrina de inteligencia que unifique los procedimientos de inteligencia de las instancias de Seguridad Nacional del Estado Mexicano. De esta manera, se promueve una cooperación entre las fuerzas policiacas y el ejército.

Esto entra en polémica con la seguridad pública a cargo de las instituciones policiales del país. El plan menciona la prevención social de la violencia como pilar fundamental junto con la contención del delito, a través de intervenciones policiales. Los principios que guiarán las políticas de seguridad 
pública contenidas en estos dos planos son planeación, prevención, protección y respeto a los derechos humanos; coordinación; transformación institucional; evaluación y retroalimentación.

La situación actual se encuentra en el mismo tenor que con el gobierno de Felipe Calderón; a pesar de las diferencias mínimas que planteaba el gobierno de Peña Nieto, se sigue llevando una estrategia punitiva de combate y lucha frontal contra el crimen organizado y las acciones delictivas. La prevención queda en el discurso y la mayor parte del financiamiento se dirige en dotar de herramientas a las autoridades encargadas de combatir el delito, tanto el Ejército como la Policía, en una cooperación mutua.

\section{Conclusión}

Hoy en día, el narcotráfico es visto como una amenaza a la seguridad nacional y pública en el país. El desarrollo histórico de la política de seguridad en México y la relación con los Estados Unidos en su combate al narcotráfico dan cuenta de ello, al tomar el narcotráfico como tema prioritario en sus agendas. En el discurso y en los hechos, no basta con sólo emplear a los órdenes de gobierno encargados de la seguridad pública para hacer frente a este problema. También se han incorporado las Fuerzas Armadas en la lucha por garantizar la seguridad nacional, debido a que el narcotráfico es considerado como un fenómeno que atenta contra el orden público y el mismo Estado.

Con el tiempo, la evolución de los conceptos se ha reflejado en los planes de Gobierno y en las leyes: la seguridad nacional se ha ampliado y cubre ámbitos desde lo económico hasta lo ambiental. La seguridad interna, que parte de esta seguridad nacional, encuentra lazos vinculantes con la seguridad pública. De tal suerte, no sólo tienen una aproximación a nivel conceptual. Ahora, también en términos operativos se puede crear un desajuste en el momento de llevar a cabo estas acciones conjuntas de seguridad. Así, se puede provocar confusión en las acciones emprendidas por parte de las autoridades y en la percepción que tienen las personas sobre éstas.

Por lo anterior, se plantea que bajo esta dinámica es necesario contar con un marco legal para aclarar las funciones y delegar responsabilidades específicas a cada uno de los órdenes de gobierno a nivel operativo. Esto con el fin de que haya una cooperación intergubernamental que no transgreda las acciones realizadas por una $\mathrm{u}$ otra instancia, con estricto apego a los derechos humanos. Sin embargo, en este trabajo, se retoma la envergadura que la política de 
combate al enemigo ha tenido para provocar la desestabilidad política, social y económica en el país.

En el panorama actual el Estado, en su lucha por mantener el poder ante el crimen organizado, ha perdido control, legitimidad y espacio. Por ello, en el presente trabajo, se propone una reconfiguración de perspectiva en el ataque al crimen organizado. Así, en lugar de que se priorice la política punitiva que se ha llevado a cabo en los últimos años, se debe volver la mirada a mejorar la economía, fortalecer la educación y la salud.

\section{Bibliografía}

Ángel, Arturo, "En cada día del 2015 asesinaron 51 personas en México”, Vanguardia. [Consulta: 12 de abril, 2016]. Disponible en: http://www.vanguardia.com.mx/ artículo/en-cada-dia-del-2015-asesinaron-51-personas-en-mexico

BARRón, DiAna, La asimétrica distribución del ingreso como amenaza a la seguridad nacional, Tesis de licenciatura, Escuela de Ciencias Sociales, udLAP, Puebla, 2003. Benítez, RAúl, "México: seguridad pública y seguridad nacional. Desafíos militares”, en La seguridad nacional integral en México, México, Universidad del ejército y fuerza armada Cesnav, 2013.

Carrasco, Jorge, "La violencia crece y Peña Nieto se pasma”, Revista Proceso, agosto, 2016. [Consulta: 17 de octubre, 2017]. Disponible en: http://www.proceso.com. $\mathrm{mx} / 450082 /$ la-violencia-crece-pena-nieto-se-pasma

Сhabat, JoRge, "La respuesta del gobierno de Felipe Calderón al desafío del narcotráfico: entre lo malo y lo peor", en Arturo Alvarado y Mónica Serrano (coords.), Los grandes problemas de México, México, Colmex, 2010.

Cunjama, Emilio, Jóvenes en riesgo, pandillas y delincuencia organizada en México, México, Tirant lo Blanch, 2014.

CuRzio, Leonardo, La seguridad nacional en México, México, unam, 2014.

Foucault, Michel, El nacimiento de la biopolítica, México, Fondo de Cultura Económica, 2010.

GonzÁlez, JaImE, “La seguridad interior en México: concepto y campo de acción”, Revista del centro de estudios superiores navales, núm. 34.

GonzÁlez, Patricia, “Seguridad estatocéntrica y derechos humanos: los peligros para la democracia”, XXVI Congreso de la Asociación Latinoamericana de Sociología, Guadalajara, México, 2007.

González, Samuel, La seguridad pública en México, México, unam, 1994.

Guerrero Gutiérrez, Eduardo, "La estrategia fallida”, Revista Nexos, diciembre, 2012. [Consulta: 24 de octubre, 2016]. Disponible en: http://www.nexos.com. $\mathrm{mx} /$ ?P=leerarticuloctArticle $=2103067$

Guerrero Gutiérrez, Eduardo, "Narcotráfico S. A.”, Revista Nexos. [Consulta: 17 de diciembre, 2017]. Disponible en: http://www.nexos.com.mx/?p=15083 
Hobbes, Thomas, Leviatán, México, Fondo de Cultura Económica, 1992.

LABOrie, Mario, La evolución del concepto de seguridad, Madrid, Instituto español de estudios estratégicos, 2011.

Lima Malvido, María DE LA Luz, "De la política criminal a la seguridad nacional”, en Sergio García y Olga González (coords.), La situación actual del sistema penal en México, XI Jornadas sobre justicia penal, México, unam - Inacipe, 2011.

Locke, John, Segundo tratado sobre el gobierno civil, México, Alianza, 2004.

López Portillo, ERnesto, "Seguridad pública y democracia: hacia la seguridad ciudadana -relativizar al poder frente a la libertad-", en Arturo Alvarado y Sigrid Arzt (coords.), El desafío democrático de México: seguridad y estado de derecho, México, Colmex, 2001.

MARInA, SAndra, "En seguridad, sexenios de avances y retrocesos”, El Financiero. [Consulta: 13 de septiembre, 2017]. Disponible en: http://www.elfinanciero.com.mx/ politica/en-seguridad-sexenios-de-avances-y-retrocesos.htlm

Martínez, Alejandro, “Tres momentos para entender la seguridad nacional en México”, Revista de El Colegio de San Luis, año 4, núm. 7, pp. 236-255. [Consulta: 12 de mayo, 2015]. Disponible en: http://www.redalyc.org/4262/426239582011.pdf

Montero, JuAn Carlos, "La estrategia contra el crimen organizado en México: análisis del diseño de la política pública”, Revista Perfiles Latinoamericanos, núm. 39.

Ortega, Carlos, "Hacia una política de seguridad y defensa de México", Revista del Centro de Estudios Superiores Navales, año 3, núm. 34, 2013.

Poder Ejecutivo Federal, Plan global de desarrollo 1976-1982. [Consulta: 13 de noviembre, 2016]. Disponible en: http://ordenjurídico.gob.mx

Poder Ejecutivo Federal, Plan nacional de desarrollo 2001-2006, p. 89. [Consulta: 3 de diciembre, 2015]. Disponible en: http://wwww.dof.gob.mx/nota_detalle. php?codigo=766334tfecha=30/05/2001

Presidencia de la RepúBlica, Anuncio de la operación Conjunta Michoacán, inicio de la nueva estrategia de seguridad de combate al narcotráfico, México, Presidencia de la República, 2006.

Ravelo, Ricardo, Los capos. Las narco-rutas de México, México, Plaza y Janés, 2006.

Rousseau, Jean-Jacques, El contrato social, México, Grupo Editorial, 2005.

Saín, Marcelo, "Condiciones institucionales del control parlamentario de las actividades y organismos de inteligencia del Estado”, Seminario sobre control democrático de los organismos de seguridad interior en la República Argentina, Centro de estudios legales y sociales, Argentina, 1997.

SANTOS, MARIO, El modelo general de administración estratégica de la seguridad nacional multidimensional, México, Centro de Estudios Navales, 2014.

Serrano, MónicA, "Narcotráfico y gobernabilidad en México", Dialnet. [Consulta: 28 de noviembre, 2017]. Disponible en: http://dialnet.unirioja.es/servlet/ articulo? codigo $=2873255$ 
Vega, Armando, "El narcotráfico de drogas: más allá de la represión”, Revista LiberAddictus, núm. 105. [Consulta: 18 de febrero, 2016]. Disponible en: http://www. liberaddictus.org/v_imprimir.php?articulo=934 